\title{
Importância da educação científica na formação docente e para o ensino de ciências: algumas reflexões pertinentes
}

\author{
The importance of scientific education in both teacher and science \\ teaching training courses: relevant reflections
}

Recebido: $19 / 06 / 2020$ |

Revisado: 22/07/2020 | Aceito: 24/07/2020 | Publicado:

$11 / 03 / 2021$

Alesson Sardinha de Moraes ORCID: http://orcid.org/00000002-1849-1181

Instituto Federal de Educação, Ciência e Tecnologia do

Maranhão/IFMA

E-mail:

alesson.ifma2016@gmail.com

Elen de Fátima Lago Barros Costa

ORCID: http://orcid.org/00000001-9790-7669

Instituto Federal de Educação, Ciência e Tecnologia do Maranhão/IFMA

E-mail: elen@ifma.edu.br

Como citar:

MORAES, A. S. COSTA, E. F. L. B.; Importância da educação científica na formação docente e para o ensino de ciências: algumas reflexões pertinentes Revista Brasileira da Educação Profissional e Tecnológica, [S.I.], v. 1, n. 20 p. 1-21, e10860, mar. 2021.

This work is licensed under a Creative Commons Attribution 4.0 Unported License.

\section{Resumo}

Este artigo tem como objetivo refletir sobre a importância da educação científica na formação de futuros professores das licenciaturas e analisar como esta formação científica pode contribuir para a compreensão crítica para o ensino de ciências. Tem como categorias de análise: educação científica, ensino de ciências, formação docente numa perspectiva crítica voltada para a aprendizagem efetivamente significativa. Para tanto, aborda estas categorias à luz do materialismo histórico dialético, tendo como referencial teórico os estudos de Marx, Engels, Chassot, Fourez, Cachapuz, dentre outros. No que concerne aos procedimentos metodológicos, trata-se de uma pesquisa exploratória e utilizam-se como técnicas de pesquisa a revisão bibliográfica e documental. Conclui-se que investigar como o ensino de ciências está sendo desenvolvido nas licenciaturas é imprescindível para a formação dos futuros docentes e, consequentemente, para sua prática em suas salas de aula. É preciso pensar a ciência para além do caráter abstrato e, portanto, inatingível. É necessário que o ensino de ciências parta do movimento do real, ou seja, ensinar ciências acompanhando a realidade e as transformações cotidianas, instrumentalizando 0 aluno a pensar criticamente esta realidade.

Palavras-chave: Educação Científica; Ensino de Ciências; Formação Docente.

\section{Abstract}

This article aims to reflect on regards the importance of science education in training of future teachers in undergraduate courses, and analyse how this scientific training can contribute to critical thinking for science teaching. This paper has considered the scientific education, science teaching and teacher training as analysis categories, concerning to a critical perspective to the effective and meaningful learning. Those categories follows the historical dialectical materialism approach, based on theoretical references, such as Marx, Engels, Chassot, Fourez, Cachapuz, and others. Regarding to the methodological procedures, it is an exploratory research carried out by both bibliographic and documentary review techniques. As a conclusion it has been reinforced the importance that thinking how science teaching has being developed in undergraduate courses is essential for the training of future teachers and, consequently how they will work in their classrooms. It is necessary to think about science beyond the abstract character and, therefore, unattainable. It is important for science teaching to start from the daily life, that is, to teach science from the reality, instructing the student to think critically about the life.

Keywords: Scientific education; Science teaching; Teacher training. 


\section{INTRODUÇÃO}

Zygmunt Bauman, na obra "Globalização: as consequências humanas", analisa que a humanidade vive uma época complexa, de grandes mudanças e de desordem mundial, em que "o que quer que se mova a uma velocidade aproximada à do sinal eletrônico é praticamente livre de restrições relacionadas ao território de onde partiu, ao qual se dirige ou que atravessa". (BAUMAN, 1999, p. 57). Esta complexidade não pode ser explicada ou compreendida do ponto de vista meramente conceitual, visto que neste fenômeno planetário "não há uma questão única que possa captar e teleguiar a totalidade dos assuntos mundiais e impor a concordância global". O mundo globalizado instável não se move em uma só direção,

[...] o mundo "que nos rodeia", o mundo que esperavam aprisionar e imobilizar num ato de representação, parece hoje escapulir ágil e rapidamente de qualquer forma consagrada; ele é um jogador (um jogador astuto, habilidoso e esperto, com certeza) que participa do jogo da verdade, e não a aposta e o prêmio que os jogadores humanos esperavam ganhar e dividir. Na síntese concisa e vívida de Paul Virilio, o mundo de hoje não tem mais estabilidade alguma; ele se move, vai de um lado para o outro, resvala o tempo todo. (BAUMAN, 2001, p. 25).

Esta "desordem" traz impactos diretos no paradigma educacional adotado pelas nações que implementam reformas visando ao atendimento das exigências deste mundo globalizado. Neste sentido, parte-se do pressuposto de que para compreendermos o fenômeno educativo é condição primordial a análise das condições objetivas em que ele está assentado, ou seja, entender o fenômeno da educação em suas múltiplas determinações, pois, como afirma Saviani (2005), não é possível compreender a história da sociedade contemporânea e a história da educação sem refletir sobre o movimento do real.

Nesta mesma linha de pensamento, lanni (2011, p. 397) "afirma que explicar a realidade não é descobrir os nexos que constituem a realidade, mas ajudar essa realidade a se constituir". A realidade, para ser analisada, refletida e explicitada necessita de uma reflexão demorada, reiterada e obstinada por parte do pesquisador, visto que "se a aparência exterior e a essência das coisas conseguissem se exprimir plenamente, toda a ciência seria desnecessária". (IANNI, 2011, p. 400)

E é nesta reflexão demorada, reiterada e obstinada que o objeto de estudo deste artigo será desvelado. Desvelar a aparência fenomênica é, sem dúvida, um dos princípios que devem nortear o trabalho do pesquisador. Debruçar-se sobre a importância da educação científica na formação dos futuros docentes e compreender como os professores que atuam nas licenciaturas percebem a importância do tratamento da ciência viva, concreta e em pleno movimento é condição imprescindível para rompermos com a lógica formal ou o ensino meramente conteudista adotado em muitos cursos de formação docente.

Como afirma Souza $(2014$, p. 10), 
[...] a ciência herda o prestígio da religião no contexto pré-moderno e assume, em boa parte, pelo menos, o papel de explicar o mundo moderno. Não existe tema que seja discutido na esfera pública de qualquer sociedade moderna que não invoque a "palavra do especialista" que fala pela ciência. Assim, o potencial da ciência de produzir efetivo aprendizado individual e coletivo está ligado e muitas vezes decisivamente condicionado, por força de seu prestígio público, a servir de instância legitimadora e primeira e decisiva trincheira da luta social e política pela definição legítima de "boa vida" e "sociedade justa". Em outras palavras: não existe ordem social moderna sem uma legitimação pretensamente científica desta mesma ordem.

Essa afirmação nos faz refletir a importância de desmistificar a ciência como um objeto mítico/fetichizado fora do alcance dos sujeitos e apenas possível de ser "manuseada" pelos intelectuais ou escolhidos iluminados. É preciso pensar a ciência como movimento e fruto da investigação obstinada do ser humano. Ciência é uma construção social e um bem inalienável de toda humanidade e é dessa forma que tem que ser pensada e tratada nos cursos de formação docente.

É neste contexto que se insere a preocupação em refletir sobre a formação docente nos cursos de licenciatura que tem como foco o ensino de ciências. Compreende-se que esta formação tem que se comprometer com a formação crítica e atuante do futuro educador, visto que o mundo contemporâneo exige dos indivíduos uma nova forma de compreensão dos fenômenos sociais, culturais, naturais e econômicos.

Eco (2005, p.06) afirma que existem quatro regras básicas para a escolha de um objeto de pesquisa, a saber: "que o tema responda aos interesses do candidato; que as fontes de consulta sejam acessíveis; que as fontes de consulta sejam manejáveis; que o quadro metodológico da pesquisa esteja ao alcance da experiência do candidato". Como pesquisadora, além destes preceitos, acrescento que um objeto de estudo tem que apresentar relevância acadêmica, científica e social e, acima de tudo, fruir das inquietações, do mal-estar e questionamentos do cotidiano, seja ele de caráter pessoal ou profissional do pesquisador.

Tendo, portanto, a convicção de que as quatro regras apontadas por Eco (2005) são pontos indiscutíveis para esta pesquisadora, detenho-me a explicitar a relevância do objeto de estudo e as inquietações/questionamentos que me impulsionam, como docente da licenciatura de uma instituição federal de ensino superior.

Considera-se imprescindível que a formação das novas gerações de docentes tenha como foco a competência técnico-científica para compreender as mudanças ocorridas na contemporaneidade, ou seja, uma formação que os prepare para sua inserção na docência, com criticidade, criatividade e expertise para que estejam atentos para as mudanças científicas, tecnológicas e sociais. A compreensão de novos contextos sociais e científicos é primordial para que o processo de ensino e aprendizagem realmente aconteça. É preciso não somente ensinar conhecimentos científicos historicamente acumulados, mas, acima de tudo, fazer ciência, oferecer aos alunos espaços escolares que estimulem essa criação e recriação da ciência. 


\section{EDUCAÇÃO CIENTÍFICA: ASPECTOS CONCEITUAIS E HISTÓRICOS}

O advento do conhecimento científico e das novas tecnologias não é um fenômeno recente, do século XXI, ainda que na atualidade evidenciem-se as transformações e a aplicabilidade na sociedade. Nas últimas décadas tais mudanças no âmbito científico afetaram e continuam afetando a vida no planeta especialmente a esfera educacional.

Desde meados dos anos 70, do século XX, eventos como o surgimento de novos métodos e técnicas científicas inseridas no cotidiano já eram objetos de estudo do escritor futurista norte-americano Ãlvin Toffler (LACERDA, 1997). Ainda que numa época de imaturidade científica e tecnológica, Toffler, baseado em suas observações e estudos, previu o surgimento de uma nova sociedade, caracterizada pelas modificações na forma de pensar, agir e viver dos indivíduos.

Dentre o surgimento de novas ideais, conceitos e concepções, está o princípio da educação científica. A expressão educação científica com o passar do tempo esteve relacionada a uma pluralidade de conceitos (SOARES, 2004). Educação científica foi também descrita por alguns teóricos e estudiosos como alfabetização científica, letramento científico, dentre outros conceitos. No entanto, ainda que considerados por alguns autores como sinônimos, outros teóricos apresentavam concepções bem distintas dos termos indicados.

Segundo Matthews (1994), alfabetização científica define-se de diversos aspectos, podendo-se partir de uma definição esotérica, que trata a alfabetização como a habilidade de identificar e definir fórmulas, até uma definição mais abrangente, ao qual correlacionam-se aspectos não somente de natureza científica, mas também de cunho social e histórico (ROSA, 2006).

Outros autores, como Lorenzetti; Delizoicov e Leite; Sousa associam a terminologia alfabetização ao processo de obtenção de uma língua, que, e a partir da compreensão de seus códigos e símbolos, torna o indivíduo capacitado ao uso de tal alfabetização em contextos práticos e sociais (LEITE ;SOUSA,1995, p.16, apud LORENZETTI; DELIZOICOV). Ademais, ainda nessa esfera, alfabetização científica é descrita como "o conjunto de conhecimentos que facilitam aos homens e mulheres fazer uma leitura do mundo onde vivem" (CHASSOT, 2000, p.19).

A constante e desenfreada inserção de novas tecnologias no cotidiano, ao longo do tempo fora acompanhada de desafios e resistência no que diz respeito à aceitabilidade e adaptação por parte dos indivíduos na sociedade. Tais dificuldades podem ser apontadas como consequências do vigente, e ainda imperceptível, analfabetismo científico, mesmo que cada vez mais camuflado pela própria tecnologia. Chassot (2003), define "é um analfabeto científico aquele incapaz de uma leitura do universo". Dessa forma, entende-se que para se compreender a sociedade é essencial ser/estar educado conforme seu contexto, logo a sociedade científica será compreendida enquanto os indivíduos forem educados cientificamente.

Além disso, a admissão e consolidação de novas tecnologias e formas de ciências como meios de facilitar e possibilitar a leitura do mundo, como sugere Chassot (2003), são temas que vêm sendo constantemente discutidos na sociedade. É nessa perspectiva que a escola, como ambiente de construção de conhecimentos e formação de indivíduos críticos, entra em pauta. Além do mais, o professor como 
intermediário do processo de ensino-aprendizagem deve indispensavelmente estar preparado para o contexto no qual está inserido. Entretanto, o real cenário atual não é o dos mais otimistas.

Segundo Moreira (1998) há um desencontro entre a prática docente e o uso de instrumentos e métodos tecnocientíficos. Nesse contexto, complementa Chassot (2003) "há situações nas quais temos docentes desplugados ou sem televisão, que ensinam a alunos que surfam na internet ou estão conectados a redes". Dessa maneira, a ideia que se tem é que a escola e o professor estão, com o passar do tempo, perdendo o papel de referência do conhecimento e do saber.

A partir de tais concepções, entende-se que o distanciamento entre professor e tecnologia tem comprometido a efetivação da educação científica das futuras gerações, à medida que os objetivos de formação de indivíduos conscientes e criticamente preparados não são, em muitos casos, concretizados.

Torna-se imprescindível, então, pensar em educação científica direcionada especificamente à formação dos docentes, uma alternativa que passa a ser vista desde meados do século XX como uma das mais viáveis no enfrentamento do analfabetismo científico. Segundo Santos (2007), a educação científica e tecnológica tende a capacitar o indivíduo não só a assimilar, como também a intervir, ativamente, nas transformações que ocorrem em seu cotidiano, além de dar-Ihes autonomia para questionamentos e reflexões sobre suas ações.

\section{EDUCAÇÃO CIENTÍFICA, O ENSINO DE CIÊNCIAS E A FORMAÇÃO DOCENTE PARA A EDUCAÇÃO BÁSICA}

Atualmente tem-se percebido com maior evidência que o ensino tradicional tornou-se, ao longo do tempo, mais incompatível com as novas gerações de estudantes. Isto porque a sociedade encontra-se em constantes processos de mudança e evolução, que exigem, principalmente nas áreas das ciências, a busca por se reinventar e criar novos métodos de ensino.

Nesse contexto, a educação científica, juntamente com o avanço tecnológico, foi apresentada nos últimos anos como uma efetiva alternativa de auxílio à busca por práticas, meios e ferramentas que possam contribuir no processo de ensinoaprendizagem.

O aluno da atual geração encontra-se no centro de três polos evolutivos, que são: ciência, tecnologia e sociedade. Sua aprendizagem tem sido, pois, baseada em tais fatores. Entretanto, o que se observa há algum tempo é a existência da lacuna entre as expectativas geradas e a realidade alcançada quanto à formação de cidadãos críticos e conscientes por meio da educação científica.

Dessa forma, tais resultados demonstram a persistente ineficácia no ensino e exercício da educação científica em determinados contextos, o que, além de um conjunto de mudanças na sociedade, tem contribuído diretamente para o fracasso da aprendizagem dos alunos como também para a rejeição e desinteresse dos mesmos pela aprendizagem de ciências. Tal situação expõe claramente a necessidade de se rever as práticas e concepções de ciências apresentadas pelos professores, e com 
isso alterar e/ou adaptar seus métodos visando assim à obtenção de melhorias no processo de ensinar cientificamente. (CACHAPUZ, 2005)

O processo de mudança de concepções e ideologias devem passar, antes de tudo, por reflexões quanto à prática docente. A ideia que se tem ao se referir a professores de ciência seja química, física ou biologia é que tais indivíduos possuem total conhecimento no que diz respeito à construção e transmissão de saberes científicos.

No entanto, contrapondo essa ideia, estudos apontam que a realidade, inclusive no ensino superior, está amplamente afastada da prática. Segundo estudos, a concepção de ciência transmitida, até mesmo para alunos que almejam à docência, é apenas uma reprodução associada a um método científico, dessa forma, colaborando para a tendenciosa formação de meros professores/reprodutores, em vez de professores preparados para um cenário de mudanças, formação continuada e vinculados à pesquisa.

Nesse contexto, é indispensável aos professores, formados e formandos, avaliarem suas concepções de ciência adquiridas e repassadas, objetivando o combate e erradicação da imagem deformada que se tem da prática e do trabalho científico. (PÉREZ, 2001)

A transição de ideias e concepções parece ainda mais complicada tratandose dos docentes de gerações passadas, o que é resultado do vínculo existente com os programas já pré-estabelecidos e dentro da zona de conforto. A educação científica vem então contrapor essa perspectiva de ensino descontextualizado e supérfluo. Entretanto, tal abordagem deverá ser adaptada à realidade social na qual se insere 0 processo educativo, tendo-se equilíbrio quanto às especificidades científicas sem esquecer da contextualização sociocultural dos discentes. (FOUREZ, 2003)

Dessa forma, é relevante pensar na formação de futuros professores, tendo como pilares dessa formação a ciência e pesquisa. Uma vez que a inserção e interferência de novas tecnologias no cotidiano tende a aumentar com o tempo, tornase necessário preparar a sociedade para tais transformações. Caso contrário, o avanço tecnocientífico continuará, como descreve Hobsbawm (1995), distante da compreensão dos indivíduos. E adverte, ainda, este autor que somente a inclusão das tecnologias não assegura a aprendizagem dos conhecimentos referentes a elas. As alterações no âmbito educacional provenientes da tecnologia tornam-se ainda mais evidentes ao fazermos uma comparação no que diz respeito à sala de aula de algumas décadas atrás.

Segundo Chassot (1998), em tempos passados a sala de aula era o centro de obtenção de conhecimentos e saberes. No entanto, com o passar do tempo, surgiram novas ferramentas e métodos de comunicação e informação, que demandam preparo e formação de indivíduos para desfrutar dos seus benefícios.

No Brasil há uma quantidade considerável de estudos e pesquisas sobre o tema da formação de professores, incluindo aspectos iniciais até a conclusão e pósformação. Em geral, os problemas aos quais estão relacionados os estudos são referentes ao ambiente escolar, à forma como os docentes são influenciados na busca de soluções para os problemas educacionais, tendo como base suas formações. Dados apontam que no XII Encontro Nacional de Pesquisa em Educação Científica (ENPEC), ocorrido na cidade de Natal/RN no ano de 2019 (ENPEC, 2019), dos 1.246 trabalhos apresentados, 263 eram sobre formação de professores e 89 sobre 
educação científica, o que corresponde a $21,10 \%$ e $7,1 \%$, respectivamente. E analisando as palavras chaves dos trabalhos sobre formação de professores percebeu-se que, no geral, os conteúdos abordados foram: codocência ${ }^{1}$, estágio supervisionado, ética e conduta profissional, ação docente, experimentação em ciências, identidade docente, dentre outros temas.

Todavia, ainda que com toda essa atenção voltada à área da docência, os resultados obtidos são considerados desproporcionais em relação às dificuldades $\mathrm{e}$ desafios apresentados por professores no processo de ensino. A falta de autonomia nas práticas docentes continua sendo vista como um dos desafios a serem superados na área da educação, apontando-se como fator contribuinte para esse problema as engessadas concepções adquiridas pelos docentes ainda no seu processo de formação. Nesse contexto, a educação científica apresenta-se como uma forma de mediar os conhecimentos teóricos necessários para identificar os problemas existentes no meio, assim como, as possíveis soluções e aplicabilidade das mesmas.

A sala de aula tem mudado com o passar dos anos e essas mudanças serão cada vez mais frequentes até pela dinâmica concreta dos processos sociais. $O$ docente que não acompanha as mudanças e as tendências, principalmente, relacionadas a ciência e tecnologia, está fadado ao fracasso, não apenas com os discentes como também para consigo mesmo no âmbito profissional. As tão faladas tecnologias hoje presentes nas escolas e demais instituições de educação são uma resposta a já defasada metodologia tradicional de ensino e ao tradicional espaço em que se dão tais práticas.

Dessa forma, o docente, como responsável pelo processo de ensinoaprendizagem, deve também intermediar a integração dos alunos a este cenário de mudanças, não só no contexto escolar, assim como prepará-los para os campos sociais. Para isso, é necessário antes de tudo repensar e refletir a par das suas concepções e práticas docentes. (MORAN, 2004)

Ao analisarmos e/ou compararmos os documentos oficiais que norteiam a formação docente nas licenciaturas e as diretrizes curriculares para o ensino de ciências percebe-se como estas questões são refletidas.

No que diz respeito à formação inicial e continuada, a Resolução $n^{0}$ 02/2015 2 (BRASIL, 2015, p. 4 grifo nosso) no tocante aos princípios desta formação, define no seu artigo $3^{\circ}$, parágrafo $5^{\circ}$ e inciso $\mathrm{V}$ que, esta deve estar baseada na "articulação entre a teoria e a prática no processo de formação docente, fundada no domínio dos conhecimentos científicos e didáticos, contemplando a indissociabilidade entre ensino, pesquisa e extensão."

Este princípio é relevante, na medida em que não se pode ensinar ciências sem articular teoria e prática. Não se pode aprender ou apreender ciências (e nenhum

\footnotetext{
${ }^{1}$ [...] vamos apresentar de forma sucinta como a codocência é apresentada na literatura. Antes, porém, precisamos dizer que o termo codocência é uma tradução nossa (SILVA, 2013) do termo inglês coteaching para se referir de forma geral a prática de dois ou mais professores em sala de aula. No entanto, o termo também já era usado em Portugal, como relata o trabalho Abelha, Martins \& Costa (2008) que apresentam uma experiência de codocência envolvendo professores de química e física para o desenvolvimento de aula interdisciplinar sobre chuva ácida.(FARROCO, FRANCO, MATTOS, SILVA, 2019, p. 01).

${ }^{2}$ Define as Diretrizes Curriculares Nacionais para a formação inicial em nível superior (cursos de licenciatura, cursos de formação pedagógica para graduados e cursos de segunda licenciatura) e para a formação continuada.
} 
conhecimento científico) sem ter como princípio básico a concepção de práxis científica. Vivenciar o conteúdo científico é apreendê-lo em sua essência, visando utilizá-lo cotidianamente no processo de transformação do real. Como afirma Marx (1985, p. 939), "toda ciência seria supérflua se houvesse coincidência imediata entre a aparência e a essência das coisas". Ele acreditava e defendia que a ciência ou o conhecimento científico deveria ser mais crítico e reflexivo.

Nesse sentido,

a formação para a docência de qualidade deve se pautar na perspectiva investigativa, na qual a pesquisa, assumida como princípio científico e educativo, apresenta-se como uma proposição metodológica fundamental para o rompimento das práticas de reprodução. (BARREIRO e GEBRAN, 2006, p. 118).

Os cursos de licenciatura devem oportunizar aos professores conhecimentos teóricos e práticos imprescindíveis ao cumprimento de suas funções, assim como transformar todos os espaços de formação em locais de aprendizagem e não somente de ensino conteudista/fragmentado. Um espaço de efetiva formação política, ética, humana e profissional.

Compreende-se, entretanto, que a dificuldade em adotar esta postura na formação dos futuros professores esteja, também, nos seguintes questionamentos: qual o paradigma educacional que está norteando a formação dos formadores? Ou seja, como foram formados os professores que atuam nas licenciaturas? Esses profissionais foram formados para articular os conhecimentos específicos de cada área e os saberes da docência?

E nesta perspectiva, analisa Viana (2012, p. 19),

Desde o seu surgimento, as licenciaturas lidam com o desafio de formar o professor de um conteúdo específico da educação básica, pressupondo-se que esses cursos devem contemplar, além dos conteúdos da ciência de referência específica, aqueles relacionados ao exercício da docência. Pesquisadores como Shulman (1987), Gauthier et al. (1998) e Tardif (2004), entre outros, vêm chamando a atenção para a complexidade de um conjunto de saberes necessários para a docência, o qual envolveria, por exemplo, além do conhecimento de conteúdo, outros conhecimentos como: i) pedagógico de conteúdo, ii) das ciências da educação, iii) do currículo da educação básica, iv) dos alunos, v) dos contextos educacionais e, vi) das finalidades educativas.

Quando Viana (2012, p. 21) reflete sobre as concepções tradicionais sobre a formação docente, em que "para ser professor não seria necessária uma formação acadêmica institucionalizada e supervisionada, uma vez que bastaria ter talento, bom senso, saber o conteúdo, ter cultura, seguir a intuição", ele afirma que esta concepção é ultrapassada e que é preciso profissionalizar a docência. 
Nas licenciaturas, é preciso ter na formação dos formadores a sensibilidade e competência técnica para articular estes saberes e, como afirma Diniz e Pereira (1999, p. 111), "para formar esse profissional, é necessário um conjunto de disciplinas científicas e um outro de disciplinas pedagógicas, que vão fornecer as bases para sua ação". Este é um pensamento cíclico, ou seja, a formação dos formadores influencia, diretamente, na atuação dos futuros professores em sala de aula.

Outra questão relevante é o grande desafio dos cursos de licenciaturas em efetivar o que é proclamado no parágrafo 6 em que se define que "projeto de formação deve ser elaborado e desenvolvido por meio da articulação entre a instituição de educação superior e o sistema de educação básica". (BRASIL, 2015, p. 5). Nos debates educacionais, esta articulação é sempre pauta de discussão, visto que as licenciaturas, em sua maioria, somente oportunizam esta aproximação nos estágios supervisionados, o que inviabiliza que o aluno sinta o "chão da escola".

E nesta linha de raciocínio afirma, Barreiro e Gebran (2006, p. 26),

De modo geral, os estágios têm se constituído de forma burocrática, com preenchimento de fichas e valorização de atividades que envolvem observação participação e regência, desprovidas de uma meta investigativa. Dessa forma, por um lado se reforça a perspectiva do ensino como imitação de modelos, sem privilegiar a análise crítica do contexto escolar, da formação de professores, dos processos constitutivos da aula e, por outro, reforçam-se práticas institucionais não reflexivas, presentes na educação básica, que concebem 0 estágio como o momento da prática e de aprendizagens de técnicas do bem-fazer.

É consensual nos debates educacionais que os licenciandos devem ter contato com a escola/sala de aula no início de sua formação, visto que este contato permitirá que ele possa confrontar a realidade com os conhecimentos teóricos apreendidos no seu espaço de formação.

Diante de todos esses desafios, está, também, a articulação dessa formação com as concepções curriculares para o ensino de ciências definidos na Base Nacional Comum Curricular/BCNN (BRASIL, 2017, 321). Neste documento, é defendido o letramento científico como sendo uma concepção de ciência,

[...] que envolve a capacidade de compreender e interpretar o mundo (natural, social e tecnológico), mas também de transformá-lo com base nos aportes teóricos e processuais das ciências. Em outras palavras, apreender ciência não é a finalidade última do letramento, mas, sim, o desenvolvimento da capacidade de atuação no e sobre o mundo, importante ao exercício pleno da cidadania.

Nesta perspectiva, o processo de investigação científica deve ser compreendido como elemento central na formação do aluno, num sentido ampliado, e cujo desenvolvimento deve ser atrelado a situações didáticas planejadas ao longo 
de toda a educação básica, de modo a possibilitar aos alunos revisitar de forma reflexiva seus conhecimentos e sua compreensão acerca do mundo em que vivem.

\section{Quadro 1: Base Nacional Comum Curricular/Ensino de Ciências}

\begin{tabular}{|c|c|}
\hline $\begin{array}{c}\text { Definição de } \\
\text { problemas }\end{array}$ & $\begin{array}{l}\text { - Observar o mundo à sua volta e fazer perguntas. • Analisar } \\
\text { demandas, delinear problemas e planejar investigações. • Propor } \\
\text { hipóteses. }\end{array}$ \\
\hline $\begin{array}{l}\text { Levantamento, } \\
\text { análise e } \\
\text { representação }\end{array}$ & $\begin{array}{l}\text { - Planejar e realizar atividades de campo (experimentos, observações, } \\
\text { leituras, visitas, ambientes virtuais etc.). } • \text { Desenvolver e utilizar } \\
\text { ferramentas, inclusive digitais, para coleta, análise e representação de } \\
\text { dados (imagens, esquemas, tabelas, gráficos, quadros, diagramas, } \\
\text { mapas, modelos, representações de sistemas, fluxogramas, mapas } \\
\text { conceituais, simulações, aplicativos etc.). • Avaliar informação (validade, } \\
\text { coerência e adequação ao problema formulado). • Elaborar explicações } \\
\text { e/ou modelos. • Associar explicações e/ou modelos à evolução histórica } \\
\text { dos conhecimentos científicos envolvidos. • Selecionar e construir } \\
\text { argumentos com base em evidências, modelos e/ou conhecimentos } \\
\text { científicos. • Aprimorar seus saberes e incorporar, gradualmente, e de } \\
\text { modo significativo, o conhecimento científico. • Desenvolver soluções } \\
\text { para problemas cotidianos, usando diferentes ferramentas, inclusive } \\
\text { digitais. }\end{array}$ \\
\hline Comunicação & $\begin{array}{l}\text { - Organizar e/ou extrapolar conclusões. • Relatar informações de forma } \\
\text { oral, escrita ou multimodal. • Apresentar, de forma sistemática, dados e } \\
\text { resultados de investigações. • Participar de discussões de caráter } \\
\text { científico com colegas, professores, familiares e comunidade em geral. } \\
\text { Considerar contra-argumentos para rever processos investigativos e } \\
\text { conclusões. }\end{array}$ \\
\hline Intervenção & $\begin{array}{l}\text { - Implementar soluções e avaliar sua eficácia para resolver problemas } \\
\text { cotidianos. • Desenvolver ações de intervenção para melhorar a } \\
\text { qualidade de vida individual, coletiva e socioambiental. }\end{array}$ \\
\hline
\end{tabular}

Fonte: BNCC (BRASIL, 2017, p. 323)

São muitas as competências a serem desenvolvidas nas salas de aula da Educação Básica, o que requer que também sejam observadas no espaço de formação. Diante disso, surge outro questionamento: como os cursos de licenciatura podem contemplar os diversos saberes requeridos na educação básica, efetivando uma formação docente que articule conhecimentos técnico-científicos e didáticopedagógicos? Defende-se que essa formação somente será realizada, tendo, nos espaços formadores, como paradigma de ensino a educação científica já explicitada.

Nesta perspectiva, pensar como o ensino de ciências está sendo desenvolvido nas licenciaturas é imprescindível para a formação dos futuros docentes e, consequentemente, como estes trabalharão em suas salas de aula. É preciso pensar a ciência para além do caráter abstrato e, portanto, inatingível. É necessário que o ensino de ciências parta do movimento do real, ou seja, ensinar ciências acompanhando a realidade e as transformações cotidianas, instrumentalizando o aluno a pensar criticamente esta realidade.

O conhecimento científico é socialmente construído e, portanto, deve estar acessível a todos, os cursos de licenciatura precisam constituir-se como ambientes estimulantes e fomentadores do "manuseio" do conhecimento científico. 


\section{CONSIDERAÇÕES FINAIS}

A sociedade mundial vem sendo, já há algum tempo, palco de grandes mudanças, em parte geradas pelo avanço tecnocientífico. Entretanto, tal fenômeno é acompanhado, além de benefícios, de pontos não tão otimistas, o que faz surgir consigo uma série de questões a serem pensadas e discutidas de forma, preferencialmente, generalizada. A disseminação não homogêneas de informações e conhecimentos relacionados à ciência e novas tecnologias é um dos atuais desafios da sociedade, para que ocorra a equalização dos direitos dos seus componentes.

É necessário que a sociedade evolua, de modo que não existam mais populações desprovidas de conhecimento científico e indivíduos passivos e submissos ao mero uso de ferramentas e reprodutores de ações.

Sendo a ciência um componente essencial da sociedade, assim como de sua própria evolução, é importante que ela esteja na pauta de discussões, ainda mais em se tratando de sua relação direta com a área da educação e ensino, ambos aspectos fundamentais à manutenção da vida.

É de conhecimento universal a existência de uma lacuna entre o conhecimento cientifico e sua difusão, problema esse que contrapõe a busca pela homogenia de uma sociedade tecno-científica. No entanto, é voltando o foco em solucionar está adversidade que se justificam os estudos e pesquisas referentes ao âmbito da formação de docentes capazes de pensar e refletir a ciência como um viés de evolução e bem-estar. Visto tal importância do conhecimento científico uma vez necessário para se manter o acompanhamento do constante desenvolvimento da sociedade, vale ressaltar a importância de se voltar o olhar para educação científica desde o processo da formação docentes, uma vez que esses serão os responsáveis por intermediarem a formação de novos cidadãos, que sejam críticos e problematizadores do seu cotidiano.

Nesse sentido, é fundamental que parta também do educador, ainda em formação, se dispor a entender e questionar o funcionamento do sistema educacional, e na medida do possível, contribuir para sua transformação, e não ser apenas um mero agente passivo do processo ensino e aprendizagem.

A educação científica, que se baseia em técnicas e conhecimentos, muitas vezes, bem específicos, deve ser acompanhada de atratividade, ludicidade, estímulo, problematização e reflexão. Isso deve ser desenvolvido desde a formação dos docentes a fim de que possam transformar seus métodos e práticas ao exercerem suas atividades. Certamente não há uma fórmula para se alcançar tais objetivos, a não ser a constante busca pelo aprimoramento daquilo que já se conhece.

Infelizmente, quando se analisa o atual cenário da sociedade global, em que são apresentadas a todo momento ideologias e concepções, por parte dos líderes mundiais, contrárias aos princípios e objetivos da educação científica, fica difícil ter expectativas de mudanças imediatas.

Em um campo que se objetiva a efetividade do processo de ensino aprendizagem com bases no avanço e desenvolvimento tecno-científico, com criticidade e criatividade, por meio de um trabalho docente eficaz e emancipado, 
entende-se que deve haver o consenso e apoio vindo de todas as áreas desde a esfera política e econômica até os setores cultural, social e, principalmente, educacional.

\section{REFERÊNCIAS}

BARREIRO, Iraíde M. de F.; GEBRAN, Raimunda A. Prática de ensino e estágio supervisionado na formação de professores. São Paulo: Ed. Avercamp, 2006.

BAUMAN, Sygmund. Globalização: As conseqüências humanas. Rio de Janeiro: Zahar, 1999.

BAUMAN, Sygmund. 44 cartas do mundo líquido moderno. Rio de Janeiro: Zahar, 2001.

BRASIL, Ministério da Educação. Conselho Nacional de Educação. Resolução n.02/2015. Brasília/DF: 2015. Disponível em:

http://portal.mec.gov.br/docman/agosto-2017-pdf/70431-res-cne-cp-002-03072015pdf/file. Acesso em: 22/04/2019.

BRASIL, Ministério da Educação. Conselho Nacional de Educação. Base Nacional Comum Curricular: educação é base. Brasília/DF: 2017. Disponível em:

http://basenacionalcomum.mec.gov.br/images/BNCC_El_EF_110518_versaofinal_sit e.pdf. Acesso em: 22/04/2019.

CACHAPUZ, António et al. A necessária renovação do ensino das ciências. São Paulo: Cortez, 2005.

CAPRA, Fritjof. O ponto de mutação: a ciência, a sociedade e a cultura emergente. Rio de Janeiro: Cutrix, 1982.

CHASSOT, Attico. Presenteísmo: uma conspiração contra o passado que ameaça o futuro. Espaço da Escola, 1998, ano 4, no28, p. 13-19. Disponível em:

https://www.scielo.br/scielo.php?script=sci_nlinks\&ref=000114\&pid=S1413-

2478200300010000900009\&Ing=pt. Acesso em: 30/02/2019

CHASSOT, Attico. Alfabetização científica: Questões e desafios para a educação. ljuí: Editora Unijuí, 2000.

CHASSOT, Attico, Alfabetização científica: Uma possibilidade para a inclusão social. Revista Brasileira de Educação, no 22, jan./abr.. 2003, p. 89-100. Disponível em: https://www.scielo.br/pdf/rbedu/n22/n22a09.pdf. Acesso em: 28/02/2019

DE ALMEIDA, Maria José PM; NARDI, Roberto. Relações entre pesquisa em ensino de Ciências e formação de professores: algumas representações.

Educação e Pesquisa. Vol.39, no.2, São Paulo abr./jun. 2013. Disponível em: https://www.scielo.br/scielo.php?script=sci_arttext\&pid=S1517-

97022013000200004\&lng=pt\&tlng=pt. Acesso em: 05/03/2019

DINIZ-PEREIRA, J. E. As licenciaturas e as novas políticas educacionais para formação docente. Educação \& Sociedade, São Paulo, n. 68, p. 109-125, 1999. http://dx.doi.org/10.1590/ S0101-73301999000300006. Acesso em 19/05/2020.

ECO, Humberto. Como se faz uma tese. 20 ed., São Paulo: Perspectiva, 2005. 
ENPEC. XII Encontro Nacional de Pesquisa em Educação em Ciências, 2019. Natal/RN, Anais, Natal: ABRAPEC, 2019. Disponível em: http://abrapecnet.org.br/enpec/xii-enpec/anais/listatrabarea_1.htm. Acesso em: 23/07/2020.

FOUREZ, Gérard. Crise no ensino de ciências? Investigações em ensino de ciências, v. 8, n. 2, p. 109-123, 2003. Disponível em:

https://www.if.ufrgs.br/cref/ojs/index.php/ienci/article/view/542/337. Acesso em: 10/03/2019

FARROCO, Célio de P.; FRANCO, Pedro Henrique F.; MATTOS, Cristiano R.; SILVA, Clauco S. F. A codocência expandida no contexto do estágio supervisionado em física. In: XII Encontro Nacional de Pesquisa em Educação em Ciências (ENPEC), 2019, Natal/RN. Anais da ENPEC, 2019. Disponível em: http://abrapecnet.org.br/enpec/xii-enpec/anais/lista_area_02_1.htm. Acesso em: 23/07/2020.

HOBSBAWM, E. O breve século XX. São Paulo, Companhia das Letras, 1995. IANNI, Otávio. A construção da categoria. Revista Histedbr. №41, vol. 11, abril 2011. Disponível em: https://periodicos.sbu.unicamp.br/ojs/index.php/histedbr/article/view/8639917. Acesso em 12/05/2019

LACERDA, Gilberto. Alfabetização científica e formação profissional. Revista Educação e Sociedade, №60, dezembro/1997. Disponível em: https://www.scielo.br/scielo.php?script=sci_arttext\&pid=S010173301997000300006\&lng=pt\&tIng=pt. Acesso em: 10/03/2019

LEITE, Sérgio A. S.; SOUZA, C. B. A alfabetização nos cursos de habilitação para o magistério. In: Cadernos de Pesquisa, São Paulo, n. 94, p. 15-24, ago., 1995. Disponível em: http://publicacoes.fcc.org.br/ojs/index.php/cp/article/view/834/1869. Acesso em: 11/03/2019

MOREIRA, V. Kenski. Novas tecnologias: O redimensionamento do espaço e do tempo e os impactos no trabalho docente. Revista Brasileira de Educação, № 8, mai./ago. 1998, seção Documentos, p. 58-71. Disponível em:

https://www.researchgate.net/publication/277042533_Novas_tecnologias_o_redimen sionamento_do_espaco_e_do_tempo_e_os_impactos_no_trabalho_docente Acesso em: $15 / 03 / 2019$

ROSA, Katemari; Cristina, M. Martins. $O$ que é alfabetização científica, afinal?. Disponível em https://www.researchgate.net/publication/242643849_O_QUE_E_ALFABETIZACAO _CIENTIFICA_AFINAL. Acesso em: 03/01/2019.

SANTOS, W. L. P. dos. Educação científica na perspectiva de letramento como prática social: funções, princípios e desafios. Revista Brasileira de Educação, no 36, set./dez. 2007, seção Documentos, p.474-492. Disponível em: https://www.scielo.br/pdf/rbedu/v12n36/a07v1236.pdf. Acesso em: 01/04/2019

SAVIANI, Dermeval. Transformações do capitalismo, do mundo do trabalho e da educação. IN: LOMBARDI, José C. (Org.). Capitalismo, trabalho e educação. 3 ed. Campinas, SP: Autores Associados, HISTEDBR, 2005. 
SOARES, Magda. Letramento e alfabetização: as muitas facetas. Revista Brasileira de Educação, [online]. 2004, n.25, pp.5-17. ISSN 1413-2478. Disponível em: https://www.scielo.br/pdf/rbedu/n25/n25a01.pdf. Acesso em: 20/03/2019

SOUZA, Jessé. Max Weber e o "racismo científico" da sociologia moderna. Idéias|Campinas (SP)|n. 8|nova série|1º semestre 2014. Disponível em: https://periodicos.sbu.unicamp.br/ojs/index.php/ideias/article/view/8649446/16001 . Acesso em: 20/03/2019

MARXI, Karl. A Ideologia Alemã. São Paulo, Centauro Editora, 1987.

MARX, K. O Capital: crítica da economia política, São Paulo: Difel Difusão Editorial S.A., 1985.

MORAN, José Manuel. Os novos espaços de atuação do professor com as tecnologias. Revista diálogo educacional, v. 4, n. 12, 2004. Disponível em: http://www.pucrs.br/ciencias/viali/tic_literatura/artigos/189117821002.pdf. Acesso em: 08/04/2019

PÉREZ, Daniel Gil et al. Para uma imagem não deformada do trabalho científico. Ciência \& Educação (Bauru), v. 7, n. 2, p. 125-153, 2001. Disponível em: https://www.scielo.br/pdf/ciedu/v7n2/01.pdf. Acesso em: 12/05/2019

VIANA, Gabriel Menezes et al . Relações entre teoria e prática na formação de professores: investigando práticas sociais em disciplina acadêmica de um curso nas ciências biológicas. Educação Revista., Belo Horizonte, v. 28, n. 4, p. 1749, Dec. 2012 . Available from <http://www.scielo.br/scielo.php?script=sci_arttext\&pid=S0102$46982012000400002 \&$ Ing $=$ en\&nrm $=$ iso $>$. access on 19 May 2020. https://doi.org/10.1590/S0102-46982012000400002. 